\title{
Men and older persons also care, but how much? Assessing amounts of caregiving in Spain and Sweden
}

\author{
By Gerdt Sundström ${ }^{1}$, Magnus Jegermalm ${ }^{1}$, Antonio AbelLÁN ${ }^{2}$, \\ Alba Ayala ${ }^{2}$, Julio Pérez ${ }^{2}$, Rogelio Pujol ${ }^{3}$ \& Javier Souto 4
}

\begin{abstract}
We estimate how much caregiving men and women respectively do, and how much of the caregiving is done by older (65+) and younger persons, inside their household and for other households, in Spain and in Sweden. To assess this, we use self-reported hours of caregiving from two national surveys about caregiving, performed in 2014 (Spain, N = 2003; Sweden, $N=1193$ ). Spain and Sweden have dissimilar household structures, and different social services for older $(65+)$ persons. Caregivers, on average, provide many more hours of care in Spain than in Sweden. Women provide about $58 \%$ of all hours of caregiving, in Spain in all age groups, in Sweden only among younger caregivers. The reason is the dominance of partner caregivers among older Swedes, with older men and women providing equal hours of care. Family caregiving inside the household is

${ }^{1}$ Gerdt Sundström \& Magnus Jegermalm, Institute of Gerontology, School of Health and Welfare, Jönköping University, Jönköping, Sweden

2 Antonio Abellán, Alba Ayala \& Julio Pérez, Centre for Human and Social Sciences, Spanish National Research Council, Madrid, Spain

${ }^{3}$ Rogelio Pujol, Instituto Nacional de Estadística, Madrid, Spain

${ }^{4}$ Javier Souto, Unión Democrática de Pensionistas, Madrid, Spain
\end{abstract}


International Journal of Ageing and Later Life

more extensive in the more complex Spanish households than in Swedish households. Family care between households prevails in Sweden, where the large majority of older persons live with a partner only, or alone. This is increasingly common in Spain, although it remains at a lower level. We estimate that older persons provide between $22 \%$ and $33 \%$ of all hours of caregiving in Spain, and between $41 \%$ and $49 \%$ in Sweden. Patterns of caregiving appear to be determined mainly by demography and household structure.

Keywords: caregivers, family care, gender, household, partner, Spain, Sweden.

\section{Introduction}

Family care is receiving increased attention in many countries due to inadequate public resources and demographic challenges such as an ageing population, increasing childlessness and older people increasingly living alone in many countries (OECD 2013, 2017; Schulz \& Eden 2016). By "family care", we here refer to caregiving by family and other kin, neighbours and others, often called "informal care." We exclude paid private care and public services such as Home Help.

A recurrent finding in population studies of family care is the dominance of female and younger caregivers, corresponding to the common notion that caregiving is primarily carried out by middle-aged persons, mostly women. Older persons (henceforth $65+$ ) are generally perceived as receivers of care, although surveys in the Nordic countries usually find rather small gender and age differences in the prevalence of caregiving. In a recent Swedish government survey, $22 \%$ of adult men and $25 \%$ of adult women reported being caregivers, with the highest rates among 45 - to 64-year-old persons (29\%) and 65- to 80 -year-old persons (26\%) (National Board of Health and Welfare 2012). Spain is a contrast, with a great surplus of female caregivers in all age groups (Abellán et al. 2017a). A less publicised finding is the fact that for Britain, the United States, Sweden and Spain, there are about an equal number of male and female (older) caregivers for partners when they live just with each other (Askham et al. 1992, with personal communication, courtesy Emily Grundy; AARP 2014; Abellán et al. 2017b). In fact, a Swedish population 
study of persons aged 75 years or more even found more older men than women caring for their partner, but mentioned this only in passing (Kristensson Ekwall 2004). A recent study more boldly announced that “Men do care!" (Wallroth 2016).

Living with just one's partner is increasingly common among middleaged and older persons in Western countries. Solitary living is also becoming more common, the shrinking remainder are various kinds of complex households (Iacovou \& Skew 2011). Spanish and Swedish studies report that most caregivers provide rather few hours but also that the less numerous persons - who are often older themselves - who care for someone in their own household often provide many hours (e.g. CIS 2014 below; NBHW 2012). This boils down to whether the prevalence of caregiving corresponds to the amount of care - henceforth the number of hours - that is provided. To assess amounts of care is difficult at best, and the amount does not always imply how critical it is. The amount of care is often assessed by questions about how many hours per day/week/month the caregiver provides. A systematic review of questionnaires used to capture amounts of caregiving shows how complex the issue is (Cès et al. 2017).

Notwithstanding these difficulties, we will attempt to estimate amounts of caregiving in Spain and Sweden. Both countries have rapidly ageing populations, the age group $65+$ make up $19 \%-20 \%$ of the population but have different long-term care policies and distinctly different household structures (Abellán et al. 2017a). Spain spends less than 1\% of its gross domestic product (GDP) on public services for older persons, Sweden about 3\% of its GDP (OECD 2013, 2017; Rodrigues et al. 2012). Yet, Spain is the only Southern European country that has rather high coverage rates of public, or publicly financed, services for older persons, a fact not widely known. For example, $4 \%$ of the $65+$ are institutionalised, the same rate as in Sweden, and 6\% use (publicly financed) Home Help, lower than Sweden's 10\% (2016 for Sweden, www.socialstyrelsen.se; Envejecimiento en Red 2017; IMSERSO 2017). Spain also has a vast supply of private home care workers, and residential care is often privately paid for by users or their families. Both countries have extensive alarm systems for older persons, and Spain has a good supply of day care, which is rare in Sweden. Spanish services have been expanding, while the Swedish 
International Journal of Ageing and Later Life

services have contracted (Ulmanen \& Szebehely 2015). In Sweden, living alone has decreased among older persons (about 40\% in the 1980s, and $32 \%$ in 2016) and about 60\% live with just their partner (Sundström 2018). In Spain, $23 \%$ of older persons live alone, a rate that is rising, and $41 \%$ live with just their partner (Abellán et al. 2017a). All these factors are likely to affect patterns of caregiving in general and also the amounts of care inside households and between households.

\section{Data and Methods}

Our objective is to assess the amounts of care men and women provide in different age groups, inside and between households in Spain and Sweden, and whether these amounts follow the same pattern as the distribution of caregivers. To do this, we use one Spanish and one Swedish survey that obtained information about hours of caregiving. The Spanish main source was a survey carried out by Simple Lógica for the Unión Democrática de Pensionistas (UDP) in $2014(N=2003$ for 16+, $N=414$ for $65+)$. For Sweden, we used the Ersta Sköndal University College survey for their Civil Society project (ESUC), also performed in 2014 ( $N=1193$ for $18+, N=385$ for $65+$ ).

Both surveys are national population samples of about the same size and with reasonably similar definitions of caregiving. In the Spanish UDP survey, subjects were asked if they cared for another person due to his/her illness or disability, helping with tasks of daily living. Caregivers for persons outside the subject's household were asked about how many hours of care they gave. Persons caring for someone in their own household were categorised as providing 24-hour round-the-clock caregiving in the original survey. We have censored this to 12 hours/day, which was the average for caregiving inside one's own household in the very large 2008 EDAD survey (Survey on Disability, Personal Autonomy and Dependency, see Oliva-Moreno et al. 2015; Abellán et al. 2017b) and also in another Spanish survey in 2014 (CIS 2014, below). In the Swedish ESUC survey, subjects were asked if they gave care to someone, inside or outside their household, with "special needs of care" due to old age, illness or disability, followed by a question about how many hours per month this amounted to. In ESUC, we maximised the number of hours to 
12 hours/day, only $2 \%$ of all caregivers reported providing more hours of caregiving than that. In the UDP survey, $2 \%$ of all caregivers for someone in another household reported providing more than 12 hours of care per day. In ESUC, with this restriction, caregivers aged 18-64 years provided on average 68 hours of care per month for someone outside their household, and 49 hours/month for someone in their household. Among older caregivers, the average amounts were higher: 77 hours and 154 hours, respectively. When they cared for a partner in their own household they provided, on average, 5 hours of care per day.

For an overview (Table 2), we use three other sources to assess how stable our findings are: for Spain the 2008 EDAD survey (Abellán et al. 2017b) and a Centro de Investigaciones Sociológicas survey in 2014 (CIS, study number 3009, 2014, $N=2472$ for 18+, for 65+ $N=578$ ), and for Sweden a 2012 government survey (NBHW 2012, $N=8202$ 18+, for $65+N=$ 2719). All of these were representative population surveys. We used the chi-square test of independence for variables in the cross-tabulations, and we also calculated a z-score test to assess differences in population proportions (percentages) between Spain and Sweden. For all tests, the significance level was set at $5 \%$. As mentioned, the UDP survey by default fixed caregiving inside one's household at 24 hours/day. If we had used that amount it would have doubled the amounts for these caregivers, but with only marginal effects on gender shares. Men's share would rise 1 percentage point, and older caregivers' share would rise 2 percentage points. The proportion of care given within the household would rise but with no change by gender. Our transformation of care given inside one's own household to the average of 12 hours/day therefore seems reasonable. As mentioned, averages for caregiving inside one's own household were about 5 hours/day in Sweden.

\section{Results}

Table 1 describes how common caregiving is among younger and older men and women. In both Spain and Sweden, women are more likely than men to be caregivers among younger persons, and the gender difference among older persons is negligible. The independence test suggests that gender is unrelated to caregivers' age; men and women care regardless 
International Journal of Ageing and Later Life

Table 1. Percentage of the population who define themselves as caregivers, by gender and age group, Spain and Sweden, 2014

\begin{tabular}{lcccccccc}
\hline & \multicolumn{3}{c}{ SPA } & SPIN & & \multicolumn{3}{c}{ SWEDEN } \\
\cline { 2 - 4 } \cline { 7 - 8 } \cline { 7 - 8 } & Men & Women & Total & & Men & Women & Total \\
\hline$<65$ & 14 & 19 & 16 & & 14 & 20 & 17 \\
$65+$ & 14 & 13 & 14 & & 20 & 21 & 21 \\
Total & 14 & 18 & 16 & & 16 & 20 & 19 \\
\hline
\end{tabular}

Chi-square test of independence, sample size: Spain $(p=0.722)$, Sweden $(p=0.342)$.

Sources: Our own computations on the UDP and ESUC surveys.

of age. Therefore, the differences in percentages between Spain and Sweden are significant in Tables 1, 4 and 5, except for younger men in Table 1.

In Table 2, we use three different Spanish and two different Swedish surveys to assess the stability of caregiving patterns. The various surveys all indicate that quite a large, but varying, proportion of caregivers are older themselves and also provide large amounts of all care. In Spain, older caregivers provide between $22 \%$ and $33 \%$ of all hours of informal care, while in Sweden they provide between $41 \%$ and $49 \%$. Spain (still) has many younger caregivers; however, most of the caregivers are in their late forties or near retirement age in both countries.

The frequency of caregiving in different age groups is consistently higher in Sweden. Variations in caregiving prevalence in one case (Instituto Nacional de Estadística 2008) are due to a quite narrow definition of caregiving (being the main caregiver), while in the rest they are probably due to random variations between different surveys.

The average number of hours of caregiving by younger and older male and female caregivers is described in Table 3.

There are both differences and similarities between younger and older Spanish and Swedish male and female caregivers. In both countries, older caregivers tend to provide more hours of care. On average, Spanish caregivers report two to four times more hours of caregiving than their Swedish counterparts. 
Table 2. Proportion of older persons among all caregivers, and in all hours of caregiving, Spain and Sweden, selected years

\begin{tabular}{lccccccc}
\hline & \multicolumn{3}{c}{ SPAIN } & & \multicolumn{2}{c}{ SWEDEN } \\
\cline { 2 - 4 } \cline { 7 - 8 } \cline { 7 - 8 } & EDAD & CIS & UDP & & NBHW & ESUC \\
\cline { 2 - 4 } \cline { 6 - 7 } & 2008 & 2014 & 2014 & & 2012 & 2014 \\
\hline \% of all carers & $33^{*}$ & 20 & & 32 & 37 \\
\% of all hours & 31 & 33 & $22^{* *}$ & & 41 & $49^{* *}$ \\
\hline
\end{tabular}

*Percentage of persons designated as main caregivers.

**Using 12 hours/day: In the very large EDAD 2008 survey, this was the average number of hours provided by persons caring for someone in the same household. The UDP survey by default set the amount at 24 hours/day for caregivers living with the cared for person. In the Swedish ESUC, we censored reports similarly, maximising reports at 360 hours/month.

Sources: Spain: INE: Survey on Disability, Personal Autonomy and Dependency, 2008 (EDAD); CIS: Survey on Care for Dependents, 2014; UDP: Survey on Caregiving, 2014. Sweden: The National Board of Health and Welfare, 2012 (NBHW); Ersta Sköndal University College Survey, 2014 (ESUC).

Table 3. Hours of caregiving among caregivers, by gender and age group, Spain and Sweden, 2014

\begin{tabular}{lccccccc}
\hline & \multicolumn{3}{c}{ SPAIN } & & \multicolumn{3}{c}{ SWEDEN } \\
\cline { 2 - 4 } \cline { 6 - 8 } Age & \multicolumn{3}{c}{ Hours/day } & & \multicolumn{3}{c}{ Hours/day } \\
\cline { 2 - 4 } \cline { 6 - 8 } & Men & Women & Total & & Men & Women & Total \\
\hline$<65$ & 7 & 7 & & & 2 & 2 & 2 \\
$65+$ & 9 & 10 & 9 & & 4 & 3 & 3 \\
Total & 8 & 8 & 8 & & 3 & 3 & 3
\end{tabular}

Sources: Our own computations on the UDP and ESUC surveys, using the restriction on reported hours described in the footnote of Table 2. Statistical means. 
International Journal of Ageing and Later Life

Table 4. Proportion of all hours of caregiving, and proportion of all caregivers, by gender and age group, Spain and Sweden, 2014 Per cent

\begin{tabular}{|c|c|c|c|c|c|c|}
\hline \multicolumn{7}{|c|}{ Proportion of all hours of care } \\
\hline \multirow{2}{*}{ Age } & \multicolumn{3}{|c|}{ SPAIN } & \multicolumn{3}{|c|}{ SWEDEN } \\
\hline & Men & Women & Total & Men & Women & Total \\
\hline$<65$ & 33 & 45 & 78 & 19 & 34 & 51 \\
\hline $65+$ & 9 & 13 & 22 & 26 & 23 & 49 \\
\hline Total & 42 & 58 & 100 & 44 & 57 & 100 \\
\hline \multicolumn{7}{|c|}{ Chi-square test of independence: Spain $(p=0.907)$, Sweden $(p=0.076)$. } \\
\hline \multicolumn{7}{|c|}{ Proportion of all caregivers } \\
\hline \multirow{2}{*}{ Age } & \multicolumn{3}{|c|}{ SPAIN } & \multicolumn{3}{|c|}{ SWEDEN } \\
\hline & Men & Women & Total & Men & Women & Total \\
\hline$<65$ & 35 & 47 & 82 & 26 & 37 & 63 \\
\hline $65+$ & 8 & 10 & 18 & 18 & 19 & 37 \\
\hline Total & 43 & 57 & 100 & 43 & 57 & 100 \\
\hline
\end{tabular}

Chi-square test of independence: Spain $(p=0.918)$, Sweden $(p=0.523)$.

Sources: Our own computations on the UDP and ESUC surveys, using the restriction on reported hours described in the footnote of Table 2.

Female caregivers in Spain and Sweden provide more hours of care, with the exception of older Swedish male caregivers who report more hours of care than older female caregivers.

This is also visible in the proportion of all care that men and women give, as shown in Table 4, which also gives the corresponding distribution of caregivers. There is no interaction between the gender and age of caregivers, and both variables are statistically independent.

Overall, there is equal overrepresentation of female caregivers in both countries among primarily younger persons (under 65), and women in general in both countries provide more hours of care. Female caregivers in Spain provide more hours in all age groups, while in Sweden this is 
Table 5. Distribution of all hours of caregiving, inside and outside, respectively, of one's household, Spain and Sweden, 2014

Per cent

\begin{tabular}{lcccccccc}
\hline & \multicolumn{3}{c}{ SPAIN } & & \multicolumn{3}{c}{ SWEDEN } \\
\cline { 2 - 3 } \cline { 7 - 8 } & Men & Women & Total & & Men & Women & Total \\
\hline Inside & 33 & 43 & 76 & & 17 & 18 & 33 \\
Outside & 9 & 15 & 24 & & 28 & 39 & 67 \\
Total & 42 & 58 & 100 & & 44 & 57 & 100
\end{tabular}

Chi-square test of independence: Spain $(p=0.608)$, Sweden $(p=0.074)$.

Sources: Our own computations on the UDP and ESUC surveys, using the restriction on reported hours described in the footnote of Table 2.

only true among younger caregivers. Amounts of caregiving - hours of caregiving - tend to follow the distribution of caregivers in Spain, but somewhat less so in Sweden. The reason is the large proportion of partner caregivers among older Swedes.

In Spain, most (three-quarters of all hours) care is provided inside one's own household, especially among male caregivers, as shown in Table 5.

Younger caregivers (under 65 years) in both countries provide the largest proportion of all care to persons in other households, while in Spain they provide $89 \%$ of all hours of care to persons "outside" (and 75\% of all "inside" care; calculations available on request). In Sweden, most (twothirds of all hours) caregiving is between separate households. The exception is older male and female caregivers, who provide equal amounts of care "inside" and "outside." Caregiving inside one's household or to persons in other households is unrelated to the gender of the caregiver, according to the independence test.

\section{Discussion}

There is a higher proportion of older caregivers in Sweden than in Spain. It is therefore not surprising that older Swedish caregivers also contribute a larger share of the total amount of caregiving than older caregivers do in 
International Journal of Ageing and Later Life

Spain's more complex household structure. Yet, Spanish households are changing, with older Spaniards increasingly living just with their partner or alone (Abellán et al. 2017a, 2017b).

In Spain, most (three-quarters) of the hours of family care are provided inside the caregiver's household, while in Sweden most (two-thirds) of the hours of family care are provided between separate households. The exception is older male and female Swedish caregivers, who provide equal amounts of care inside and outside their own household. This is expected, as younger Swedish caregivers often provide care to parents and others living elsewhere, while older caregivers often provide care for a partner, and frequently for many hours. Our analyses suggest that older persons provide 2 to 3 hours out of 10 hours of informal care given in Spain, and about double in Sweden. Generally speaking, partnered persons provide more care, inside and outside their own household, than persons who live alone (calculations not shown here). The latter probably have fewer potential receivers and may also suffer disabilities due to their, on average, higher age.

Spanish caregivers on average provide many more hours of care than Swedish caregivers, probably due to the more complex Spanish household structure, higher disability rates of older Spaniards and less available public services. For example, a third of Spanish older people still live in various complex households, which is very unusual in Sweden (Abellán et al. 2017b). Disability rates are about double among older Spaniards compared to older Swedes (OECD 2013). More extensive Home Help services in Sweden than in Spain may influence informal caregiving, as there can be a certain "trade-off" between informal and formal care (Jiménez-Martín \& Vilaplana-Prieto 2012). This should mostly affect caregiving to persons in other households, as Home Help services primarily target persons who live alone. Public Home Help services provide few hours of care in both Spain and Sweden, suggesting marginal effects on the patterns we have seen. Nevertheless, support provided under the Spanish Dependency Law introduced in 2007, which reimbursed caregivers, might have contributed to more caregiving inside the caregiver's household up to 2012 when, due to the economic crisis, some benefits were cut.

As mentioned, Spain spends a much smaller proportion of its GDP on public services for older persons than Sweden (Rodrigues et al. 2012; 
OECD 2013, 2017). The difference is probably due to higher co-payments, use of migrant care workers and other private, out-of-pocket paid services in Spain. The economic crisis in Spain (2008 and after) has checked the development of social services; therefore, more care and associated costs have remained with or returned to the family.

A limitation of our study is that amounts of caregiving - whether measured as hours of providing care or otherwise - are notoriously difficult to assess, which is visible in the spread between the different surveys. One reason is that the boundary between socialising and caregiving is opaque. Some studies include socialising and "monitoring" in caregiving and in two major Swedish surveys, seven out of ten caregivers provide "social company, stimulation and entertainment," which is the single most common support that is provided (Busch Zetterberg 1996; NBHW 2012). When the giver and receiver of care share a household, caregiving becomes even more opaque than in the case of inter-household support (Cès et al. 2017). A Swedish study which compared caregivers' recalled time use and their time diaries found that most caregivers underestimated the amounts of time they gave. This was particularly true for older and female caregivers (Flyckt et al. 2011). A person with dementia or severe disability may need help or monitoring-supervision 24 hours a day (Wimo \& Nordberg 2006). As mentioned, we use the average of 12 hours/day for caregiving inside one's household in the Spanish UDP survey, as this appears to be a reasonable approximation of the amount of care provided. It is also conservative; use of the original default amount of 24 hours in the survey would have emphasised older caregivers even more.

Our cross-sectional data cannot disclose how much care is provided over the life course. Caregiving accumulates over time and therefore is more common over a longer period than in a cross-sectional study, as shown in a study from the United States (Butrica \& Karamcheva 2014), but we do not know of any study that has recorded how much time caregivers have spent altogether in these longer (or repeated) commitments. Perhaps this is unknowable.

With all these limitations, older persons emerge as important family caregivers. We also find that men are caregivers more often than commonly thought, both with regard to how often they give care, and how much care they provide. This is particularly the case among older Swedes, where men perform at least as many hours of caregiving as women, 
International Journal of Ageing and Later Life

mostly caring for their partner. This supports an early study by Chappell which found gender differences in caregiving, but these gender differences vanished in cases of severe needs of the partner (1989).

Another intriguing issue is the content of the care given. Men and women may be doing different things; for example when a son and a daughterin-law help an elderly person, the man may be doing house repairs (not always recorded in surveys about caregiving), while the woman may be performing personal care, cleaning and other house work. Both "male" and "female" tasks can be essential for keeping the recipient in her/his home, but at least some men also perform traditionally "female" tasks. It is sometimes noticed that men receive more praise for their helping and caregiving than do women (Milne \& Hatzidimitriadou 2000). This may be due to the fact that male caregiving in general has been overlooked. An early study analysed the division of labour between wife and husband when caring for older relatives and suggested that the role of husbands had been neglected (Litwak \& Kail 1980).

The importance of older caregivers, for partners and others, seems to be an effect of older persons being increasingly of better health, and more often living with a partner, illustrated by an avalanche of golden weddings in Sweden (Lennartsson et al. 2017). These demographic factors appear to explain the important role of men and older persons in general in the Swedish panorama of caregiving. They are somewhat less important in Spain, but are probably increasing. The often overlooked significance of older caregivers in general and of (older) male caregivers suggests a future convergence in patterns of care.

Future caregiving may also depend on factors such as postponed disability, family size, household type, technological changes, home improvements and cultural norms. As mentioned, there are also indications of cutbacks in Swedish social services, which may affect caregiving (Ulmanen \& Szebehely 2015). Yet, demographic changes, especially the increasing joint survival of older men and women who live just with each other, may be the intrinsic factors in the patterns we have described. When men increase their caregiving, gender inequalities may diminish (Larrañaga et al. 2008) and potential consequences of caregiving - negative and positive - may affect men as often as women. 
Men and older persons also care, but how much?

\section{Acknowledgements}

Unión Democrática de Pensionistas, Madrid, has generously permitted us to re-analyse their 2014 survey on caregiving in Spain, and also allowed one of their experts to collaborate with the authors.

We gratefully recognise financial support from ENVACES, Plan Nacional I+D+I, Ref. CSO2015-64115-R; LONGPOP, European Union's Horizon 2020 Programme, Ref. 676060; and a research stipend from The School of Health and Welfare, Jönköping.

The authors would also like to thank two anonymous reviewers for their suggestions.

\section{Corresponding Author}

Gerdt Sundström, Institute of Gerontology, School of Health and Welfare, Jönköping University, Box 1026, SE-55111 Jönköping, Sweden. Email: gerdt.sundstrom@ju.se

\section{References}

AARP. (2014). Family Caregivers Providing Complex Chronic Care to Their Spouses. Washington, DC: AARP Public Policy Institute.

Abellán, A., Pérez, J., Ayala, A., Pujol, R. \& Sundström, G. (2017a). Dependencia y cuidados. [Dependency and caregiving]. In Informe España 2017. Madrid, Universidad Pontificia de Comillas, Cátedra JM Martín Patino. Available on http://www.informe-espana.es/ wp-content/uploads/2017/11/05-C3-Dependencia.pdf (Accessed: February 9, 2018).

Abellán, A., Pérez, J., Pujol, R., Sundström, G., Jegermalm, M. \& Malmberg, B. (2017b). Partner care, gender equality, and ageing in Spain and Sweden. International Journal of Ageing and Later Life 11(1): 69-89.

Askham, J., Grundy, E., Tinker, A. \& Hancock, R. (1992). Caring: The Importance of Third Age Carers. Research Paper Number 6. London: Age Concern Institute of Gerontology, King's College.

Busch Zetterberg, K. (1996). Det civila samhället $i$ socialstaten: inkomstkällor, privata transfereringar, omsorgsvård [Civil society in the welfare state: Sources of income, transfers, care]. Stockholm: City University Press. 
International Journal of Ageing and Later Life

Butrica, B. \& Karamcheva, N. (2014). The Impact of Informal Caregiving on Older Adults' Labor Supply and Economic Resources. Washington, DC: The Urban Institute.

Cès, S, De Almeida Mello, J., Macq, J., Van Durme, T., Declerq, A. \& Schmitz, O. (2017). A systematic review of questionnaires used to measure the time spent on family care for frail older adults. International Journal of Care and Caring 1(2): 227-245.

Centro de Investigaciones Sociológicas (CIS). (2014). Encuesta de cuidados a dependientes. Microdatos [Survey on Care for Dependents. Microdata]. Madrid: CIS. Available on http://www.cis.es/cis/opencm/ ES/2_bancodatos/estudios/ver.jsp?estudio $=14078 \&$ cuestionari$\mathrm{o}=16878 \&$ muestra=22481 (Accessed: February 15, 2018).

Chappell, N. (1989). Health and helping among the elderly. Journal of Aging and Health 1(1): 102-120.

Envejecimiento en Red (2017). Estadísticas sobre residencias: distribución de centros y plazas residenciales por provincia [Statistics on nursing homes: Units and number of beds by province]. Informes Envejecimiento en Red, n. 18. Available on http:/ / envejecimientoenred.es/download/ estadisticas-sobre-residencias-distribucion-de-centros-y-plazas-residenciales-por-provincia-2017-6/ (Accessed: February 15, 2018).

Flyckt, L., Löthman, A., Jörgensen, L., Rylander, A. \& Koenig, T. (2011). Burden of informal care giving to patients with psychoses: A descriptive and methodological study. International Journal of Social Psychiatry 59(2): 137-146.

Iacovou, M. \& Skew, A.J. (2011). Household composition across the new Europe: Where do the new Member States fit in? Demographic Research, 125(14): 465-490. doi: 10.4054/DemRes.2011.25.14

IMSERSO. (2017). Información estadística del Sistema para la Autonomía y Atención a la Dependencia (SAAD). Datos de Gestión [Statistical information on public services for dependent persons. Administrative data]. Instituto de Mayores y Servicios Sociales [Institute for Older Persons and Social Services]. Madrid. Available on http:// www.dependencia.imserso.es/ dependencia_01/documentacion/estadisticas/est_inf/datos_estadisticos_saad/index.htm (Accessed: February 15, 2018).

Instituto Nacional de Estadística (INE). (2008). Encuesta de discapacidad, autonomía personal y situaciones de dependencia, EDAD. Microdatos. [Survey on Disability, Personal Autonomy and Dependency. 
Microdata]. Madrid: INE. Available on http://ine.es/dyngs/INEbase/es/operacion.htm? c=Estadistica_C\&cid=1254736176782\&menu=resultados\&idp=1254735573175 (Accessed: February 15, 2018).

Jiménez-Martín, S. \& Vilaplana-Prieto, C. (2012) The trade-off between formal and informal care in Spain. European Journal of Health Economics 13(4): 461-490.

Kristensson Ekwall, A. (2004). Informal caregiving at old age. Bulletin No. 16. Dissertation, Lund University, Department of Nursing, Faculty of Medicine.

Larrañaga, I., Martin, U., Bacigalupe, A., Begiristáin, J.M., Valderrama, M.J. \& Arregui, B. (2008). Impacto del cuidado informal en la salud y la calidad de vida de las personas cuidadoras: análisis de las desigualdades de género [The impact of caregiving on health and quality of life of caregivers: Analysis of gender differences]. Gaceta Sanitaria 22(5): 443-450. Available on https:// doi.org/10.1157/13126925.

Lennartsson, C., Sundström, G. \& Wikström, P. (2017). De äktenskapliga långkörarna [The Long Running Marital Unions]. Statistics Sweden: Välfürd 4: 8-19.

Litwak, E. \& Kail, B. (1980). Family Structure, Sex Roles, and Some Social Costs to Helpers of Aged Depressives. Columbia University, The Center for the Social Sciences, New York. Mimeo.

Milne, A. \& Hatzidimitriadou, E. (2000). "Isn't he wonderful?". Exploring the contribution and conceptualization of older husbands as carers. Ageing International 28(4): 389-407.

National Board of Health and Welfare (NBHW). (2012). Anhöriga som ger omsorg till närstående - omfattning och konsekvenser [Family Caregiving Extent and Consequences]. Stockholm: Socialstyrelsen.

OECD. (2017). Preventing Ageing Unequally. OECD iLibrary. Available on https:/ / www.oecd-ilibrary.org/employment/ preventing-ageingunequally_9789264279087-en (Accessed: March 9, 2018).

OECD/European Commission. (2013). A Good Life in Old Age? Monitoring and Improving Quality in Long-term Care. OECD Health Policy Studies, OECD iLibrary. Available on http://www.oecd.org/els/ health-systems/a-good-life-in-old-age-9789264194564-en.htm (Accessed: March 9, 2018).

Oliva-Moreno, J. Peña-Longobardo, L.M. \& Vilaplana-Prieto, C. (2015). An estimation of the value of informal care provided to dependent people in Spain. Applied Health Economics and Health Policy 13(2): 223-231. 
International Journal of Ageing and Later Life

Rodrigues, R., Huber, M. \& Lamura, G. (eds.) (2012). Facts and Figures on Healthy Ageing and Long-term Care. Europe and North America. Occasional Reports Series 8. Vienna: European Centre. Available on http://www. euro.centre.org/detail.php?xml_id=2079 (Accessed: March 9, 2018).

Schulz, R. \& Eden, J. (2016). Families Caring for an Aging America. Washington, DC: The National Academies Press.

Sundström, G. (2018). Den fasta grunden [The Solid Foundation]. Stockholm: Familjen först. In press.

Ulmanen, P. \& Szebehely, M. (2015). From the state to the family or to the market? Consequences of reduced residential eldercare in Sweden. International Journal of Social Welfare 24(1): 81-92.

Wallroth, V. (2016). Men do care! A gender-aware and masculinity-informed contribution to caregiving scholarship. Dissertation, Linköping Studies in Arts and Science, No. 674.

Wimo, A. \& Nordberg, G. (2006). Validity and reliability of assessments of time comparisons of direct observations and estimates of time by the use of the resource utilization in dementia (RUD)-instrument. Archives of Gerontology and Geriatrics 44(1):71-81. 